\title{
Enlightenment of Miao Cultural Art to Modern Design
}

\author{
Qing Wu*, Hong Peng, Xianfeng Ai \\ Department of industrial design, the college of Art and Design \\ Wuhan University of Science and Technology \\ Wuhan, China \\ Email: wuqingalysha@163.com
}

\begin{abstract}
The Miao ethnic people gave birth to the unique cultural art. Their aesthetic taste is also different from others. Under the situation of globalization, people try to discuss the cultural characteristics of Miao ethnic design art in order to establish cultural self-confidence. Furthermore, it is necessary to explore Miao's design thinking and methods. Therefore we can draw lessons from Miao's design art. It is important to understand the symbols of Miao decorative arts scientifically and analyze the design ideas of Miao so as to tap the essence of their thought. Some new ideas will be produced to the modern design. And the diversification development of modern design will be promoted through the integration of multi-cultures. By using the digital means of modern design, the national culture can be inherited and carried forward. As a result, modern design will be promoted.
\end{abstract}

Keywords—Miao People; cultural art; symbol; enlightenment

\section{INTRODUCTION}

As we all know, the Miao culture is rich and unique. It is neither entirely a farming culture nor a nomadic culture. It is both farming and traveling. Miao culture is the inexhaustible source of Miao design art. Miao people love life; they decorate life with beautiful colors, vivid and exquisite patterns. From clothes to architecture, they are all full of charming artistic atmosphere. Miao people advocate nature, love nature, follow the concept of sustainable development, and live in harmony with nature. In the development of the Miao culture, the Miao people use the decorative art symbols which have rich national characteristics to inherit the national culture and create colorful decorative art symbols. And these artistic symbols can become an important element of modern design, which increase national charm to the modern culture.

\section{Miao Cultural Characteristics}

In the culture of Miao nationality, the most prominent feature is that following the natural rules and the union of heaven and human is deeply rooted. Secondly, the Miao culture has very strong inclusiveness. During the development of the Miao history and culture, due to the frequent migrations and the frequent communication of foreign cultures, Miao people

The national social science foundation art program "research on the development of cultural and creative products based on the evaluation standard of the museum". Project no. : 17BH160.

Humanities and Social Sciences project of Hubei Provincial Department of Education (Research on competitiveness and evaluation systemof independent industrial design institutes in Hubei, Department of Education) Project No.: 17Q038) hold a tolerant and open attitude to foreign cultures, constantly absorbing foreign cultures and integrating them, thus forming a multi-cultural integration. This is also an important factor for the development of Miao culture and art. Miao culture has strong religious belief. Miao people have great respect and worship of their ancestors. They use a variety of totem symbols to express their hope of blessing and admiration for their ancestors. Since the reform and opening up, with the improvement of traffic conditions, Miao village is no longer closed and less developed. Miao people welcome the guests from all over the world with a new appearance. The culture and art of the Miao people attract countless tourists with their unique charm. Tourists from all over the world come and pay a visit to Miao Village to enjoy travelling so that Miao's tourism culture is booming. Lots of museums, shops, Restaurants and family hotels were already built up, tourists live in Miao

village personally experience the different life of the Miao, buying souvenirs with local characteristics, appreciating the Miao song and dance, tasting Miao cuisine, to understand the history and culture of Miao, and even conquered by the art of the Miao people. With the flourishing development of tourism, the Miao culture spread to the whole world and integrated into the torrent of globalization. [2]Miao culture owns rich and colorful art forms; a variety of forms of art spread the Miao culture. At the same time to express their religious beliefs and aesthetic taste. Most of the Miao people live in remote areas, the natural living environment is relatively poor, [4]Miao culture is the crystallization of their living wisdom in the harsh environment. The Xijiang Qianhu Miao village museum systematically displays the culture and art of the Miao people. Among them there are many exhibits with national characteristics, and what the most impressed in mind is Fig. 1, a flower of braided embroidery, Fig. 2 is batik of butterflies and flowers, and the shape of a butterfly feathers. These exhibits are cultural and creative products displayed in the museum. It is also a precious tourist souvenir. 


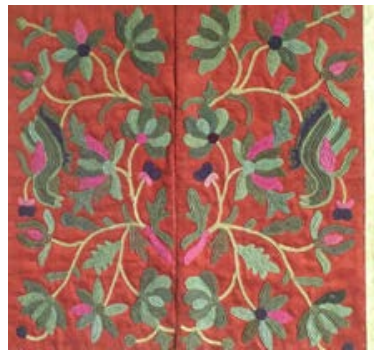

Fig. 1. Braided embroidered flower.

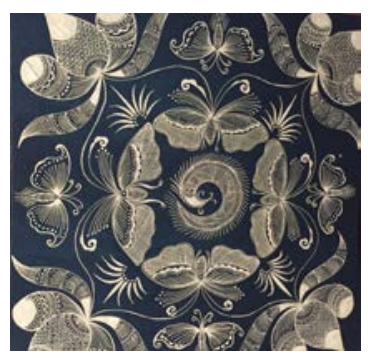

Fig. 2. Batik clothe (butterfly).

Daily items designed by Miao people are the carriers of Miao culture, also an important way of cultural transmission. Their basic necessities are simple and practical. Since most people are designers, producers and users, Miao's design focuses on user experience. For example, the building is a stilt house built mainly of wooden structures, adapting to the local environment. Clothes are made of cotton, hemp, using green and environmentally friendly textile, batik craft. Miao people staple food is rice, most of them planted rice, while fish in the water, without fertilizers and pesticides. Miao girls are dexterous, using hands to create a beautiful art world. Miao boys are ethnic originality, produced many beautiful silverware, musical instruments. Lusheng is a Miao instrument with unique shape. The design of the article is not only practical, but also has aesthetic characteristics, reflecting the unity of function and shape due to Miao's originality in the design of creation. In particular, clothing, Miao Embroidery and jewelry are daily necessities, but also with aesthetic value of art. Miao are good at drawing with the inspiration from the natural arts, these designs described fully love of life, respectful feeling to the nature. The simple and free form of expression is the real "Obey the natural rules." In the era of economic globalization and the era of Internet and information technology development, on the one hand the Miao culture spread widely to the world, and on the other hand hammered by some foreign cultures. Based on mutual exchange and communication with foreign cultures, forming a union of modern national culture, therefore Miao culture and design art can continue to develop.

\section{Cultural Connotation of Miao Decorative ART SYMBOL}

Miao ancestors were open-minded, with a wealth of imagination and amazing creativity. Unbridled art practices, bold exaggeration, the deformation of the composition and modeling. Whether it is the sun, the moon, the stars, or the flowers and insects, they are beautiful and charming because of their imagination. Using the unobtrusive manner to depict various life forms in nature, it fully embodies the vivid artistic features in the traditional Chinese culture. Miao decorative arts have great varieties, such as Miao costumes, Miao silver and so on, they are the most distinctive representatives. Various types of decorative arts have a wide variety of graphics and symbols. The most typical art symbols associated with religion and ethnic emblem include the following:

\section{A. Butterflycharacter}

[3]The butterfly symbol accumulates the primitive consciousness of Miao people worshiping ancestors and is the most typical decorative art symbol. Corresponding to a large variety of butterflies in nature, the Miao people have many artistic ways to represent butterflies. Colors and forms in different poses and with different expressions. See Figure 3. Butterfly Totem. Miao people think that the butterfly is the ancestor of the Miao people, a large number of costumes in the butterfly symbol of respect and worship of ancestors, reflecting a certain extent, the complex of reproductive worship. Many events in the Miao Festival have a direct relationship with butterflies, and the festival of drum tracks is the god of worshiping gods and butterflies.

\section{B. Dragons symbol}

[3]Miao's dragons are different from the images of the Han nationality dragons. The dragons in the Miao nationality's clothing are free to change their freedom and integrate the image of various totems worship into one. Buffalo head and horn, shrimp, snake body, tail and so integrated into the image of the image of the Miao Long, shown in Figure 4. Dragon pattern symbol is a common motif used in Miao clothing.

\section{Horn symbol}

[3] Cattle are loyal partners of Miao ancestors and the animals that depend on them. The Miao people regard cow horn as totem to show the cow worship, and cow horn becomes a typical Miao decorative art symbol. The most typical example of Miao women wearing ox horn silver crowns on their heads is also the physical manifestation of ancestor worship. The silver horn of the Leishan Miao girl is an ornament worn only for grand festival activities and marriage. See Figure 5 silver horns headdress and silver collar. Silver horn along with the girl's graceful figure fluttering in the wind, magnificent dignified add a few light and lively. Wearing holiday costumes and wearing silver headgear, girls are dancing to the drum music is the most beautiful scenery in Miao culture and art.

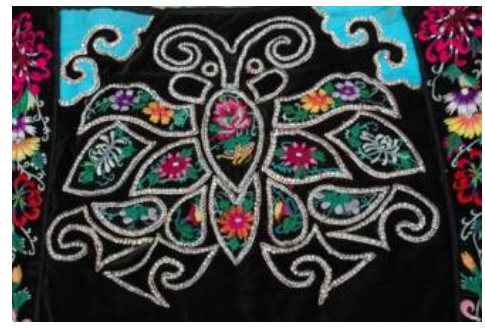

Fig. 3. The butterfly totem. 


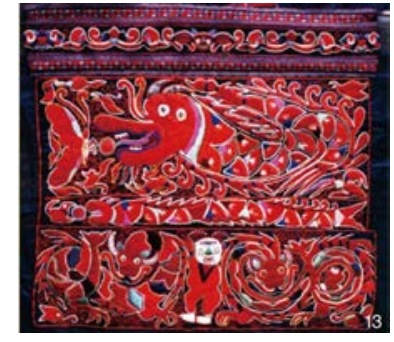

Fig. 4. Miao dragon grain symbol.

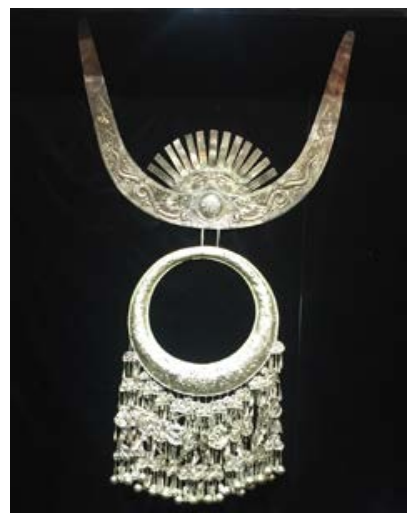

Fig. 5. Silver ox horn head and collar.

The several Miao decorative art symbols mentioned above have been developed from original religious symbols to artistic decorative symbols. Therefore, these artistic symbols have dual function, which is not only the totem of ancestor worship, but also the artistic symbol of aesthetic function.

\section{Enlightenment of Miao Culture And ART to Modern DESIGN}

Miao's culture and art have enlightenment and reference for modern design. The design philosophy of the integration of Heaven and man of Miao is consistent with the modern ecological design. In general, Miao's design culture is the unity of humanity and ecology. Decorative art symbols of the Miao nationality also provide abundant material with modern design. These symbols also bring a lot of design inspiration for the modern designer. Such as butterfly, horn symbols, dragon totem symbols, there are all kinds of flowers and birds, various pattern, color bright, full of strong national characteristics. These adornment art symbols can be used in clothing, daily necessities, and advertising, packaging, as well as tourist souvenirs. All these symbols have made the modern design with the Miao culture background and emitting the charm of traditional culture.

\section{A. Combine the Miao culture decorative arts symbols with modern design}

Miao embroidery is a precious intangible cultural heritage with colorful patterns. Miao embroidered charm lies in its bold use of color. No taboo in the color, for example, they boldly use of red with green, purple with green, purple with black. As a result, Miao embroidery has reached an exaggerated and harmonious effect. Such as the Miao people in the southeast of
Guizhou are dressed in red, orange and sky blue embroidery. Red is widely used in thematic pattern, and is set off by black base cloth. Therefore the whole picture is very clear and harmonious, three-dimensional, extremely strong sense of hierarchy. Miao decorative patterns can be extracted. All these patterns used in bags, clothing, scarves are very beautiful. They appear not only fashion, but also full of national characteristics. When Miao decorative patterns applied to the design of modern clothing, the shape and color appear new and unique. Miao girl's festival dress is elegant, colorful, with silver headdress and collars, filled with festive atmosphere as shown in the Miao ethnic festival. The clothing of the Miao is closely associated with nature, and it shows the beauty of nature. It expresses the idea of man and nature merge into one. The Miao people have the reputation of "clothing clan". Their clothing was described as "living fossil of Chinese clothing history". Miao nationality dress pattern is numerous, color is gorgeous, the pattern is rich, the design is varied, together with the craft is exquisite unique, the silver ornament of glittering and shining is beautiful. The modern clothing that use Miao nationality's adornment art design, modeling is unique, color collocation is ingenious. Figure 7 is the clothing that blends into the Miao elements. Figure. 8 is a reference to the decorative arts of the Miao nationality. The colors are bright and rich.

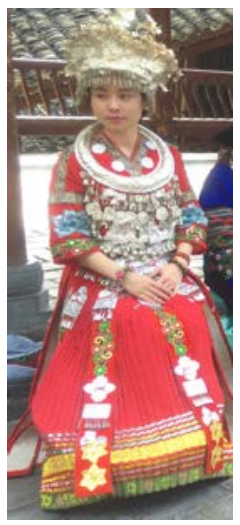

Fig. 6. Miao festival costumes.

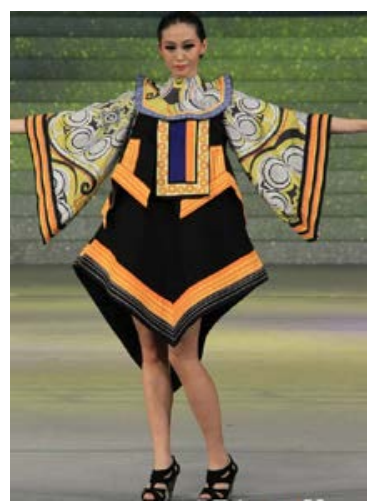

Fig. 7. Clothing of Miao elements. 


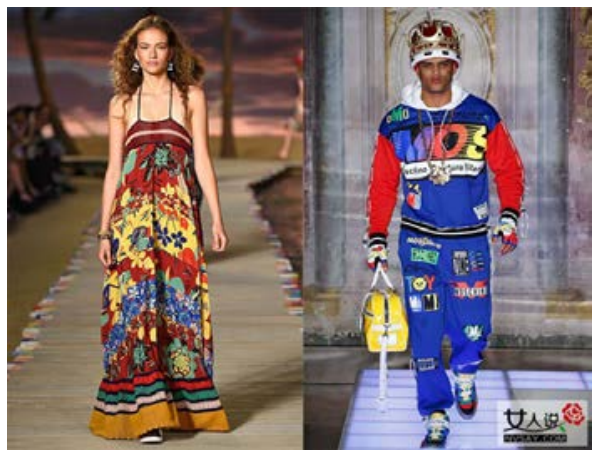

Fig. 8. Costume of Miao decorative art.

On the whole, modern clothes shown in Fig. 7 and 8 produced by a variety of techniques used in combination with a variety of Miao decorative art symbols. The colors are matched with freedom and the composition is distinctive. As a result, these garments are dazzlingly, colorful and vivid national art features, reflecting the perfect blend of modern and national clothing design.

As shown in Figure 9, the bag is designed by Suzhou Art College students according to the decorative features of Miao Embroidery. The bag is embroidered with vibrant butterflies, flowers, colorful. It has tassels with unique style. Drawing on the embroidery process of Miao embroidery and the textile printed fabric with pattern designed; the textile prints are simple, orderly, and elegant in color, suitable for the sofa of the bedroom. Figure 10 Miao embroidered sofa towel. It is an effective way to preserve and inherit the Miao culture through preserving the unique value of Miao handicrafts, carrying forward the spirit of artisans, re-creating Miao decorative art symbols and making them fashionable and aesthetic in modern products.

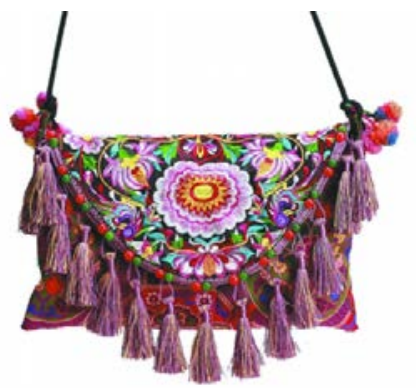

Fig. 9. Miao embroidery satchel.
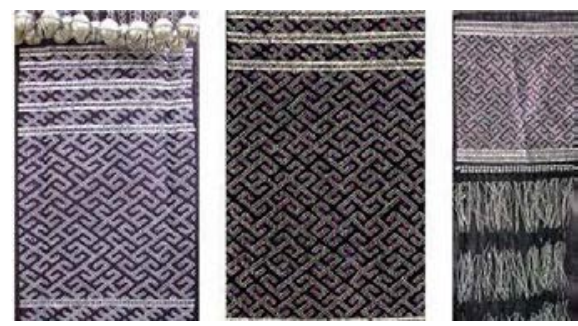

Fig. 10. Sofa scarves.

\section{B. Using local materials, according to local conditions, follow the concept of green design}

Most of the product designs of Miao choose natural materials, such as wood, cotton, bamboo and other natural materials. Traditional and environmentally friendly processing methods usually applied. Hard-working and wise Miao people use bracken to make artifacts. It is a typical green design. The fern braid is mainly made from the fern stem, and this raw material gives the fern braid a different characteristic. Because the fern stem contains bitter element and cellulose so the fern braid is not easy to be mildew, not easy to change color, variation, thus the fern braid has a unique style. As shown in figure 11 , the fruit plate is made with ferns. Figure 12 is a pendant lamp with a fern pole. These products are novel, practical and full of national characteristics. In addition, the traditional handicraft will be inherited.

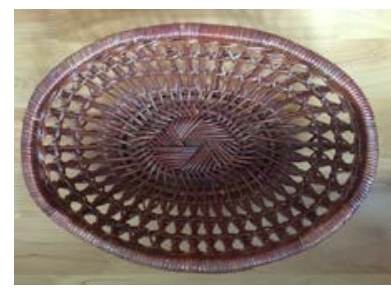

Fig. 11. Fern platter.

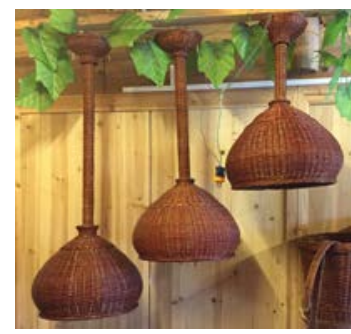

Fig. 12. Fern chandelier.

\section{Miao silverware modeling and technology and modern jewelry design}

Miao silverware processing, [1] are all done by handoperated family workshops.[6]In modeling design, Miao silversmiths are good at drawing inspiration from other arts, and make innovations in the overall shape, details and local depictions. After silversmiths design and processing, pieces of silverware have their own characteristics, dazzling. Figure 13 is a silver-tipped fin and silver comb. Silver finch can fly in the wind. It is both with costumes and a daily routine used to fix the hair utility. In short, the Miao silverware has exquisite style, exquisite workmanship, though only a small jewelry is gorgeous full of vivid charm. Miao nationality silver jewelry and Miao nationality's dress collocation is natural integration. Modern designers, with modern aesthetic perspective, combined traditional elements of ethnic minorities with modern advanced technology to create a line with modern aesthetic fashion jewelry. As a result these jewelries not only have national characteristics, but also have international characteristics. Designers can look for national roots from the traditional culture, trace the ancestral footprint, can find the direction of the development of modern design. Progress in 
social development does not mean that we can abandon the traditional national culture. On the surface, witchcraft, mythology and totem culture may be incompatible with modern society. However, modern designers can find the relevance of traditional culture and modern social culture. Instead of the traditional shape of Miao people's jewelry big, heavy, and complex, we design small, light, simple jewelry .For example, the use of elements designed by Miao elements Pisces bracelets and bull head pendants shown in Figure 14, Figure 15, modeling simple, stylish and sophisticated. They are full of fun.

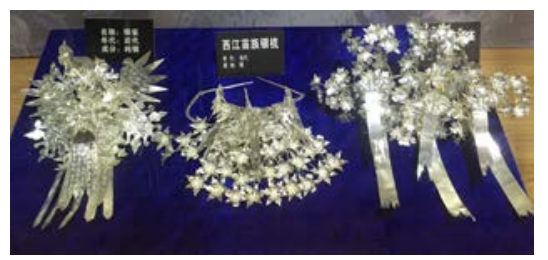

Fig. 13. Silver finches and combs of Miao.

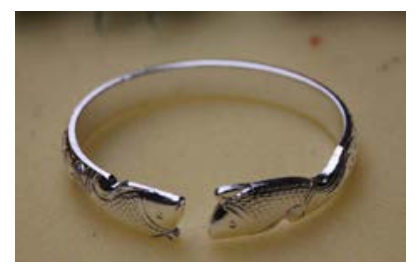

Fig. 14. Double fish bracelet.

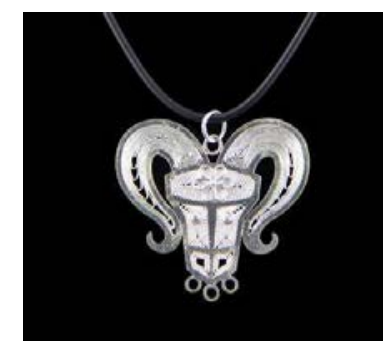

Fig. 15. Bullhead pendant.

\section{Establish Cultural Self-Confidence, Use of}

AdVANCED SCIENCE AND TeChNOLOgy to PROMOte the DEVElopMENT OF MiaO CUlTURE

Through practical investigation and visit the museum to systematically study the Miao culture, fully aware of the social value of the Miao culture, enhance the public identity of national culture. On this basis, we can establish self-confidence of the Miao culture. Only under the premise of cultural selfconfidence, we can better inherit and carry forward the national culture. It is necessary to maintain the artistic characteristics of the Miao culture as well as to absorb foreign cultures. It is necessary to combine advanced modern science and technology with ethnic culture and promote the development of the Miao culture with the times. For example, people can use advanced production technology to create rich ethnic silverware. In the ancient city of Phoenix, I am pleased to see by marriage modern forging techniques with hand-made, the fine silver and silverware can be produced. These works fully demonstrated the artistic features of the Miao and effectively dragged down the development of the Miao culture.

\section{CONCLUSION}

Miao culture is a unique part of Chinese native culture, a treasure of China's splendid culture and historical wealth. [7]Miao culture continues to flourish in its integration with foreign cultures. The design of Miao obeys the objective laws of nature and reflects that human, things and environment interact with each other coordinated design concept. In essence, the design of the Miao is to protect the environment, rational use of natural resources, maintain the ecological balance of the sustainable development. The decorative arts of Miao nationality have unique aesthetic appeal. Therefore numerous traditional national elements have a great use in modern design. Contemporary design is neither to abandon the traditional culture of the nation nor to copy. Once the relationship between national traditional culture and contemporary design has been severed, contemporary design has become passive water. National culture and modern design is a complementary relationship. The only way to develop modern design is to extract the essence from national culture and art, to inspire the creativity and imagination of design, and to innovate. Handmade products have a lot of living and development space in the modern market. Handmade products have become the synonym of high-end and individuality, which is also the irreplaceable support of many top brands. In fact, international famous clothing, jewelry, leather shoes, furniture and other brands rely on handicraft support. Designers must combine traditional craftsmanship with modern technology. Only by using advanced digital technology can the Miao decorative art patterns be preserved and widely used in modern design. Consequently, let the ancient Miao decorative art become active, gradually adapt to the modern society. People should not only promote the Miao culture, but also let the Chinese modern design with national characteristics go to the world.

\section{REFERENCES}

[1] The fusion of Miao nationality's visual culture and modern design. [J]Decoration 2016.03

[2] Brief analysis on the influence of Miao's jewelry modeling art on modern jewelry design.

[3] Lu xiao yun. Decorative art symbol in Miao costume [J] Nantong university journal. 2009.09

[4] Yu ji ping. Research on Miao decoration art [J] Decoration 2004.08.

[5] Tan hua. Interpretation of the cultural connotation of Miao nationality costumes in Guizhou. [J] journal of Guizhou university. Art version. 2008.03

[6] Wang xiao qin; Cheng si. Elements of Miao silver and modern jewelry design rumination [J]. Popular literature and art. 2014.03

[7] Cheng si, Wang xiao qin. Simple analysis of Miao nationality silver jewelry elements and cultural connotation $[\mathrm{J}]$ art science and technology. 2014, 27 (2): 276-276 